\title{
The Influence of Vocabulary and Productive Vocabulary Knowledge on Spoken English
}

\author{
ZhangDonghua \\ Nanchang Institute of Science \&Technology, Nanchang 330108,China
}

Keywords: Productive vocabulary, Oral English teaching, Linear regression, Structural equation, Vocabulary.

Abstract. In order to study the effects of vocabulary and productive vocabulary on oral English learning, this paper proposes a new analysis method based on linear regression and structural equation model, and the students are studied as subjects based on oral English learning. The results obtained by the linear regression analysis showed that both productive vocabulary and vocabulary can affect the performance of English spoken language, and the effect of vocabulary is larger than productive vocabulary. The results of the structural equation modeling show that the vocabulary and the productive vocabulary have a synergistic effect on the spoken English. Finally, comprehensive test results show vocabulary and productive vocabulary can be used by learners, but there are stages of the differences, so that the quality of oral English learning is different, which is great significance for the teaching of spoken English.

\section{Introduction}

Vocabulary and productive vocabulary have important effects on the study of spoken English. Many studies have indicated that vocabulary knowledge is an important factor in listening, reading and writing [1-3]. But so far, the effect of vocabulary knowledge on the spoken English expression is still relatively small.

Oral English is a kind of real-time advanced complex processing activity, in which the process includes three stages that are respectively conceptualization, formation and pronunciation. In the conceptual stage, the spoken language needs a clear intention, activation and expression information, to establish grammar and pronunciation structure [4-6]. In the pronunciation stage, the expression of spoken language needs to be divided into syllables according to the structure and characteristics of the vocabulary, and the use of pronunciation syllable is to express the pronunciation [7-8]. The expression of spoken language is the integration of semantics, word meaning and grammar information, and vocabulary and productive vocabulary play an important role in the production of spoken language.

\section{The Influence of Vocabulary and Productive Vocabulary on Spoken English}

Vocabulary knowledge is generally divided into the depth and breadth, namely vocabulary, or it is divided into receptive vocabulary and productive vocabulary. The breadth of vocabulary refers to understand the meaning of vocabulary, and the depth of vocabulary refers to the cognitive level and the construction of the brain [9-11]. Vocabulary knowledge is divided into two types of acceptance and production, the receptive vocabulary refers to listening or reading vocabulary, and productive vocabulary refers to oral expression and writing vocabulary. Receptive vocabulary focus on the pronunciation and meaning of audition feeling, and productive vocabulary pay attention to the expression of vocabulary depth processing and extraction.

Oral English expression is the depth of the extraction and processing of vocabulary, grammar and so on. Because of the lack of the effects of the productive vocabulary and spoken English research, the influence mechanism and effect degree are not clear. However, the effect of vocabulary on oral English learning has been recognized, and the output of spoken language should be processed by the depth knowledge of word meaning, grammar, morpheme, and so on [12-14]. The mechanism of the interaction between the productive vocabulary and the vocabulary on spoken language is worthy of 
further analysis. This study combines quantitative analysis and qualitative analysis, the analysis of two dimensions of vocabulary knowledge vocabulary and productive vocabulary can find the influence on both oral English learning, which put forward constructive suggestions for oral English teaching. This paper analyzes the mechanism of oral English Learning [15,16]:

(1) Do vocabulary and productive vocabulary have an important impact on the spoken language?

(2) What do the synergistic effect of vocabulary and productive vocabulary on spoken English learning?

(3) What is the characteristics of real time processing for the spoken language expression of the vocabulary and productive vocabulary, and how to influence the spoken language expression?

For the above problems, this paper will select the English speaking class students as research object, to carry on the targeted testing. At the same time, we study the oral English learning and teaching vocabulary and productive vocabulary from the quantitative and qualitative two dimensions.

\section{Research Methods}

Test object. This study selects the first grade students of college English school as the research object, in which they are divided into 6 classes, there are a total of 180 students, 95 girls, 85 boys, the average age is 19.25 , and the standard deviation is 0.03 .

Test tools. The study of testing tool is the spoken English test of vocabulary and productive vocabulary, in which the vocabulary test is multiple choice questions, and test finds synonyms for the given words. The test of productive vocabulary is used to fill in the blanks, the test requirement is supplementary sentences missing words according to the first three words, if there are a mistake in spelling, the plural and the temporal grammar, they do not score. The test procedure is as follows $[17,18]$ :

(1) Each person invied professional English teachers write 20 argumentative topic according to the topic examples, the sample is "why do more people pick up hobbies are?", and "how do mobile phones affect your study?". Test subjects include work, learning, life, education, science and technology culture and so on.

(2) The issue carries out audit, we delete not-consistent with the topic of discussion, we final retain 168 test questions;

(3) Inviting a parallel classes do not participate the test students on the subject to censorship, to eliminate the difficult questions.

(4) Inviting other parallel classe students carry out evaluation on the difficulty of the subject, and draw topic difficulty coefficient;

(5) According to the test standard, the difficulty coefficient is lower than 0.4 , and the remaining has 135 test questions;

(6) The remaining issues carry out the arrangement number;

(7) This study uses random number generator to generate the number of 30 questions, we print the number corresponding to the test; the oral English test uses time speech manner, students can randomly select one to answer after three weeks, the answer time is 5 minutes.

Test procedure. This paper uses the method of testing with the church for the vocabulary and productive vocabulary, the test time is 60 minutes, and the test results in the second week begins the oral test [19]. When speaking test, we will invite teachers with spoken language test score, and test a class every day to avoid fatigue effect; the whole score has a high reliability and operability, the average score of the subjects was the average score of a number of teachers, and the reliability of the teacher's score was 0.92 , to carry on the data analysis.

\section{Test Result Analysis}

In order to study the influence of vocabulary and productive vocabulary on oral English, we use vocabulary and productive vocabulary as the independent variable and English speaking performance as the dependent variable, and then the use of linear regression analyzes the performance data. The analysis results are shown in Table 1. 
Table 1. Linear regression analysis results

\begin{tabular}{|l|c|c|c|}
\hline Enter regression equation & $\mathrm{P}$ & $\mathrm{R}^{2}$ & $\Delta \mathrm{R}^{2}$ \\
\hline Vocabulary & 0.00 & 0.21 & 0.20 \\
\hline Productive vocabulary & 0.04 & 0.21 & 0.20 \\
\hline
\end{tabular}

Table 1 shows the linear regression analysis results of vocabulary and productive vocabulary, the results show that their cooperative effect of oral performance are $20 \%$; when vocabulary is 0.00 , it will enter into the regression equation; productive vocabulary is 0.04 , it will enter into the regression equation. This shows that compared with the vocabulary and productive vocabulary, vocabulary is more on the impact of oral performance

In order to further study the medium effects of vocabulary and productive vocabulary, this paper takes vocabulary as independent variable on the productive vocabulary and English speaking performance to carry out linear regression analysis, and records the change of the regression coefficient beta; this paper takes vocabulary and productive vocabulary as independent variable on the productive vocabulary and English speaking performance to carry out linear regression analysis and to observe the change of the $\beta$ value, if the change of the $\beta$ value shows that productive vocabulary plays a role in intermediate effect. The results of the analysis are shown in Table 2.

Table 2. Productive vocabulary intermediary effect form

\begin{tabular}{|c|c|c|c|}
\hline Project & B & SE & $\beta$ \\
\hline Vocabulary & 0.001 & 0.00 & $0.32^{* * *}$ \\
\hline Vocabulary and productive vocabulary & 0.001 & 0.00 & $0.18^{*}$ \\
\hline F & \multicolumn{3}{|c|}{$56.28^{* * *}$} \\
\hline $\mathrm{R}^{2}$ & 0.20 \\
\hline
\end{tabular}

In Table 2, it can be seen that the vocabulary is significant on the contribution of English speaking and productive vocabulary, when productive vocabulary gets into the regression equation, the vocabulary will have been reduced on the regression coefficient of English speaking performance $\beta$, but it still has a significant.

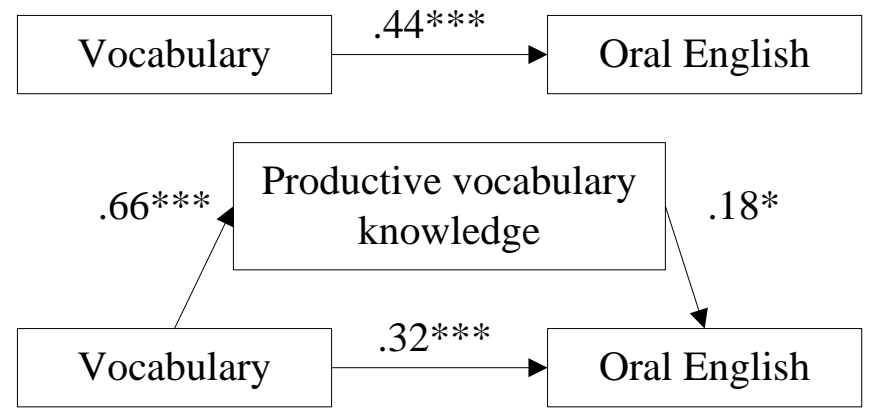

Fig. 1 Analysis of vocabulary and productive vocabulary structure model equation

Figure 1 shows the vocabulary and productive vocabulary on the analysis results of the spoken language structural model, it can be seen that the vocabulary can be used as an intermediary in the oral English, but also the indirect effects of the oral English is used as an intermediary by the productive vocabulary.

\section{Summary}

In view of vocabulary and vocabulary, this paper tests the effect and mechanism of the oral English learning, and analyzes the test results of the linear regression and structural equation model. The analysis of test results found that the learners of oral English can cooperative processing on the vocabulary and productive vocabulary. However, in different stages there are significant differences in speed, accuracy and synergy, resulting in oral English learning accuracy and fluency are different. The effect of vocabulary on spoken English is higher than productive vocabulary, and the effect of the intermediate effect on the spoken language is influenced by the medium of the productive vocabulary. 


\section{References}

[1] L.F. Bai, C.Y. Dai. different levels. The influence of of different levels and dimensions vocabulary knowledge on reading and writing. Vocabulary knowledge, 2013, 72(2): 78-79.

[2] X. Li. The research on the relationship among vocabulary, vocabulary depth knowledge and language ability. Foreign language teaching and research, 2014(5): 35 -352.

[3] C.H. LV, B. Song, Y. Wang. The comparative study of oral English test score standard. Foreign language teaching and research, 2014(6): 444 - 446.

[4] L. Zhang, Z.L. Wen, J.T. Hou. Intermediary effect test procedure and its application. Journal of psychology, 2014(5): 620 - 614.

[5] X.D. Zhang. Research on the relationship between vocabulary knowledge and language listening comprehension. Foreign language field, 2014(2): 42-36.

[6] X.D. Zhang, Y.H. Chen. The effects of memory components on the listening comprehension. Modern foreign languages, 2014(3): 360 -369.

[7] J.F. Wang. Application of hierarchical teaching strategies in University Chinese teaching. Chinese Education Innovation Herald, 2013, 47(1): 66)-67.

[8] Y. Yang. The advantages and disadvantages of multimedia teaching in English teaching. Journal of Jilin radio and Television University, 2014(6): 146-147.

[9] Y.H. Zhang. Study on the dynamic evaluation model of web writing teaching in College English. Foreign language circles, 2013(4): 73-81.

[10] X.Q. Wang. Theory and practice of higher mathematics teaching mode. Jilin education, 2014(11): 20- 21.

[11] D.H. Mao. Research on the implementation of higher vocational mathematics teaching. Journal of Chongqing Vocational and Technical College, 2014,16(4): 43- 44.

[12] S.M. Su. Study on the job burnout of American teachers. Education data digest, 2014(3): 209-217.

[13] L.J. Ceng, X.C. Wu. Review of teacher burnout research. Education research, 2013(11): 79-81.

[14] L. Jiang, F.G. Tang, Z.C. Xiao. Review of foreign teachers' job burnout research. Education and occupation, 2014(5): 65-67.

[15] B.P. Chen, A.L. Hu. Analysis of the stratified teaching mode of higher education popularization stage. Liaoning radio and TV University Journal, 2013(2): 51- 52.

[16] X.Y. Liu. Research and practice on higher vocational colleges "higher mathematics" level teaching assessment method. China out of school education, 2013(3): 101 - 111.

[17] X.F. Han. Analysis of higher mathematics teaching current situation and thinking on the stratification teaching. Journal of Lvliang College, 2014, 23(1): 40- 41.

[18] L. Fu. The application of hierarchical teaching in English teaching. Hope monthly, 2013(8):100-101.

[19] X.Q. Yu. "Matthew effect" formation and breakthrough in basic education. Teaching and management, 2013(9): 60-61. 